\title{
FRACIONAMENTO DO ALUMÍNIO POR TÉCNICAS DE DISSOLUÇÕES SELETIVAS EM ESPODOSSOLOS DA PLANÍCIE COSTEIRA DO ESTADO DE SÃO PAULO(1)
}

\author{
Maurício Rizzato Coelho ${ }^{(2)}$, Pablo Vidal-Torrado ${ }^{(3)}$, Xosé Luiz Otero \\ Perez $^{(4)}$, Vanda Moreira Martins ${ }^{(5)}$ \& Felipe Macías Vázquez ${ }^{(4)}$
}

\begin{abstract}
RESUMO
Apesar das modernas e sofisticadas técnicas disponíveis, procedimentos de extração seletiva ainda são de considerável valor para a caracterização dos solos e para o entendimento dos processos pedogenéticos, sobretudo em ambientes e solos pouco estudados, como as restingas e os Espodossolos no Brasil. A aplicação dessas técnicas - a maioria rotineiramente utilizada para a caracterização de horizontes espódicos e Espodossolos - a um conjunto expressivo de horizontes e perfis em cronossequências é inédita para esses ambientes e possibilitou estabelecer comparações com aqueles intensivamente estudados sob clima temperado ou boreal. Apesar das reconhecidas limitações dos procedimentos analíticos de dissolução seletiva, os aqui utilizados foram relativamente efetivos, o que possiblitou discriminar horizontes, inferir componentes mineralógicos e discutir processos atuantes no conjunto de horizontes e de perfis analisados. Estes se situam nos municípios de Bertioga, Cananeia e Ilha Comprida (SP), onde foram descritos e amostrados 31 perfis representativos de solos sob vegetação de restinga. Entre os resultados encontrados, destacam-se: $\mathrm{NaOH} 0,5 \mathrm{~mol} \mathrm{~L}^{-1} \mathrm{em}$ temperatura ambiente extraiu, em média, 22 a $30 \%$ mais $\mathrm{Al}\left(\mathrm{Al}_{\mathrm{n}}\right)$ que os reagentes ditionitocitrato $\left(\mathrm{Al}_{\mathrm{d}}\right)$, oxalato $\left(\mathrm{Al}_{\mathrm{o}}\right)$ e pirofosfato $\left(\mathrm{Al}_{\mathrm{p}}\right)$ para todo o conjunto de amostras. Em alguns horizontes espódicos bem drenados (Bs, Bhs, Bh e Bsm), o pH e as interações
\end{abstract}

(1) Parte da Tese de Doutorado apresentada à Escola Superior de Agricultura "Luiz de Queiroz" - ESALQ/USP. Realizada com auxílio da CAPES e FAPESP. Recebido para publicação em dezembro de 2008 e aprovado em maio de 2010.

(2) Pesquisador do Centro Nacional de Pesquisa em Solos, Embrapa Solos. Rua Jardim Botânico 1024, Jardim Botânico, CEP 22460000 Rio de Janeiro (RJ). E-mail: mauricio@enps.embrapa.br

(3) Professor do Departamento de Ciência do Solo, Escola Superior de Agricultura "Luiz de Queiroz" - ESALQ/USP. Caixa Postal 09, CEP 13418-900 Piracicaba (SP). Bolsista do CNPq. E-mail: pablo@ciagri.usp.br

(4) Professor do Departamento de Edafología de la Universidad de Santiago de Compostela. Campus Universitario Sur. Faculdad de Bioloxía. Espanha. E-mail: xl.otero@usc.es; felipe.macias.vasquez@usc.es

(5) Professora do Curso de Geografia da Universidade Estadual do Oeste do Paraná - UNIOESTE. Campus de Marechal Cândido Rondon, Rua Pernambuco 1777, Centro, CEP 85960-000 Marechal Cândido Rondon (PR). E-mail: mmartins@unioeste.br 
entre as diferentes técnicas $\left(\mathrm{Al}_{\mathrm{n}}-\mathrm{Al}_{\mathrm{o}}, \mathrm{Al}_{\mathrm{o}}-\mathrm{Al}_{\mathrm{p}}, \mathrm{Al}_{\mathrm{p}} / \mathrm{Al}_{\mathrm{o}}\right.$ e $\left.\mathrm{Al}_{\mathrm{p}} / \mathrm{Al}_{\mathrm{d}}\right)$ sugerem a formação e manutenção de compostos inorgânicos amorfos de Al em detrimento da total complexação do elemento à matéria orgânica iluviada. Esta última forma de $\mathrm{Al}$ predomina nos Espodossolos Hidromórficos.

Termos de indexação: ditionito-citrato, oxalato de amônio, pirofosfato de $\mathrm{Na}, \mathrm{NaOH}$ $0,5 \mathrm{~mol} \mathrm{~L}^{-1}$ a frio temperatura ambiente, restinga, podzolização.

\title{
SUMMARY: FRACTIONATION OF ALUMINUM BY SELECTIVE DISSOLUTION TECHNIQUES OF SOILS ON THE SÃO PAULO STATE SANDY COASTAL PLAIN
}

\begin{abstract}
In spite of modern and sophisticated techniques, procedures of selective dissolution are still of considerable value for soil characterization and to the understanding of the pedogenetic process, especially environments and soils poorly studied, as the coastal plain regions and Spodosols of Brazil. The application of these techniques commonly used for characterization of spodic horizons and soil profiles for large amount horizons and soils studied in cronossequences are rare for those environments and become possible to establish comparisons with those intensively studied under boreal and temperate climatic. In spite of the recognized limitations of all selective dissolution techniques these used procedures were relatively selective and become possible (a) the differentiation of the horizons, (b) deduce mineralogical components of soil, and (c) deduce pedogenetic process. The studied soils are situated in Bertioga, Cananeia and Ilha Comprida counties, São Paulo State, where were opened, make the morphological descriptions and sampled thirty-one pedons. The main results reached are: cold 0,5 $\mathrm{MNaOH}$ extracted in average 22 to $30 \%$ more $A l$ than dithionite-citrate $\left(A l_{d}\right)$, oxalate ammonium $\left(A l_{o}\right)$ and Na pyrophosphate $\left(A l_{o}\right)$ for all group of samples. In some well drained spodic horizons $(B s, B h s$ and Bsm) the chemical properties $(\mathrm{pH})$ and the relationship among the different techniques $\left(A l_{n}-A l_{o} ; A l_{o}-A l_{p} ; A l_{p} / A l_{o} ; A l_{p} / A l_{d}\right)$ allowed to deduce about the formation and maintenance of low cristallinity Al minerals to the detriment of this element bounded to soil organic matter. This last form of Al predominates in the hidromorphic Spodosols.
\end{abstract}

Index terms: dithionite-citrate, oxalate ammonium, Na pyrophosphate, Cold 0,5 mol L-1 $\mathrm{NaOH}$, restinga, podzolization.

\section{INTRODUÇÃO}

Procedimentos de extração seletiva, envolvendo reagentes como pirofosfato de sódio, oxalato ácido de amônio e ditionito-citrato-bicarbonato (DCB) ou ditionito-citrato (DC), têm sido amplamente utilizados no entendimento de processos pedogenéticos de muitos solos (Blume \& Schwertmann, 1969). Estudos dessa natureza são úteis e muitas vezes suficientes na avaliação da (i)-mobilização de compostos orgânicos de $\mathrm{Al}$ e Fe (Sauer et al., 2007) e inorgânicos de Si, Al e Fe (Anderson et al., 1982), bem como nos estudos de translocação de vários elementos durante o processo de podzolização (Skjemstad et al., 1992a) e descrição do grau de desenvolvimento dos Espodossolos e solos afins (Mokma \& Buurman, 1982; Barrett \& Schaetzal, 1992; Lumdström et al., 2000; Jansen et al., 2005).

A despeito de muitos avanços na aplicação de modernas técnicas na caracterização dos solos e argilas, esses procedimentos analíticos ainda são de considerável valor (Paterson et al., 1993). Exemplo disso é o recente trabalho de García-Rodeja et al. (2004), os quais utilizaram várias técnicas de dissoluções seletivas a fim de avaliar o fracionamento de $\mathrm{Al}$ em solos europeus sob influência vulcânica. A utilidade desses métodos, no entanto, é limitada, quer pela existência, na maioria dos solos, de um continuum entre componentes de baixo grau de cristalinidade até cristalinos (García-Rodeja et al., 2004), quer devido à mais débil tendência de o $\mathrm{Al}$ formar oxidróxidos, comparativamente ao Fe (Shoji \& Fujiwara, 1984; Kaiser \& Zech, 1996; García-Rodeja et al., 2004).

Todas as limitações dos métodos devem ser consideradas na interpretação do significado dos resultados que utilizam extrações seletivas em estudos de mecanismos de podzolização ou para fins de classificação taxonômica (McKeague \& Day, 1966). O DCB, por exemplo, é um extrator efetivo para óxidos de Fe livre nos solos sem discriminação de fases (Mehra \& Jackson, 1960; Farmer et al., 1983), mas extrai parcialmente aluminossilicatos não cristalinos (Farmer et al., 1983) e gibbsita, não devendo ser 
utilizado para formas de Al (García-Rodeja et al., 2004), uma vez que a fração dissolvida pelo extrator não é bem definida para esse elemento (Farmer et al., 1983). Isso é corroborado nos trabalhos de Farmer et al. (1983) e Paterson et al. (1993), os quais determinaram que o ditionito foi menos efetivo na extração de $\mathrm{Al}$ e Si do que o oxalato em muitos solos, particularmente no horizonte B (Paterson et al., 1993). Este último extrator é o mais efetivo para formas de $\mathrm{Fe}, \mathrm{Al}$ e $\mathrm{Si}$ em horizontes espódicos (Farmer et al., 1983).

Considera-se que o $\mathrm{Al}$ extraído por oxalato representa a soma do $\mathrm{Al}$ presente na alofana (Parfitt \& Henmi, 1982; Kodama \& Ross, 1991) e em alguma imogolita, em complexos orgânicos (McKeague \& Day, 1966; McKeague et al., 1971; Parfitt \& Henmi, 1982; Kodama \& Ross, 1991; García-Rodeja et al., 2004), e, em menores conteúdos, pode representar o elemento substituído na estrutura de óxidos de Fe de baixa cristalinidade (Parfitt \& Henmi, 1982; Parfitt \& Childs, 1988), bem como pode extrair uma pequena fração do elemento da gibbsita (Parfitt \& Childs, 1988; Kodama \& Ross, 1991) e do Al-hidroxi entrecamada de argilas silicatadas 2:1 (Shoji \& Fujiwara, 1984; Farmer et al., 1988; Iyengar et al., 1981). Para determinados solos, representa o pool de $\mathrm{Al}$ lábil, com potencial para regular a solubilidade do elemento na solução do solo (Takahashi et al., 1995), bem como proporciona razoável estimativa do total de $\mathrm{Al}$ translocado no perfil (Childs et al., 1983).

Ferro extraído por oxalato relaciona-se à dissolução total ou parcial de ferridrita, lepdocrocita, maghemita e magnetita (Farmer et al., 1983), além do elemento complexado à matéria orgânica (McKeague et al., 1971), o que complica a interpretação do conteúdo do Fe extraído com oxalato em alguns solos (Baril \& Bitton, 1969). No entanto, é a melhor técnica de dissolução seletiva de rotina para quantificar ferridrita nos solos, e seu uso deve ser encorajado para tal fim (Parffit \& Childs, 1988), bem como possibilita estimar, razoável e quantitativamente, a alofana em Espodossolos e outros solos com ocorrência desse mineral (Parffit \& Henmi, 1982; Farmer et al., 1984).

Uma questão ainda não resolvida refere-se a qual extrator proporciona a melhor estimativa do $\mathrm{Al}$ e Fe complexados à matéria orgânica - importante nas considerações acerca da gênese dos solos (McKeague \& Sheldrick, 1977). Pirofosfato de sódio $0,1 \mathrm{~mol} \mathrm{~L}^{-1}$ tem sido utilizado como extrator seletivo para $\mathrm{Al} \mathrm{e} \mathrm{Fe}$ em complexos orgânicos nos solos (McKeague, 1967; Childs et al., 1983; Farmer et al., 1983; Shoji \& Fujiwara, 1984). Como esses elementos estão predominantemente associados à matéria orgânica nos horizontes espódicos, o pirofosfato é geralmente considerado o melhor extrator para materiais amorfos nesses horizontes (Mokma, 1983). No entanto, nem todo o $\mathrm{Al}$ extraído nessa forma é necessariamente associado à matéria orgânica (Bascomb, 1968; McKeague \& Schuppli, 1982).
A interpretação do extrato pirofosfato, particularmente com relação ao Fe, tem sido tema de debates contínuos desde que Higashi et al. (1981) e Jeanroy \& Guillet (1981) demonstraram que tanto as formas orgânicas como as inorgânicas de Fe de baixo grau de cristalinidade podem ser simultaneamente extraídas pelo extrator (Paterson et al., 1993). No entanto, McKeague et al. (1971), trabalhando com complexos sintéticos, mostraram que o Fe extraído por pirofosfato é, em grande parte, orgânico - fato também constatado por Farmer et al. (1983) em amostras de imogolita e protoimogolita sintéticas, bem como de horizonte espódico (Bs) com baixo conteúdo de $\mathrm{C}\left(7,00 \mathrm{~g} \mathrm{~kg}^{-1}\right)$. Segundo esses autores, o pirofosfato foi seletivo para complexos orgânicos de $\mathrm{Al}$ e Fe e os discrimina efetivamente de formas inorgânicas. Acrescentam ainda que, em horizontes espódicos mais ricos em matéria orgânica dos que eles estudaram, o pirofosfato pode peptizar óxidos de Fe cristalinos (Jeanroy \& Guillet, 1981) e, em solos mais ricos em argila, o extrator promove sua dispersão (McKeague, 1967).

Em trabalho mais recente, Kaiser \& Zech (1996) afirmaram que o extrator pirofosfato não deveria mais ser usado para estimar metais em complexos húmicos. Segundo esses autores, tanto o conteúdo de Fe como o de $\mathrm{Al}$ associados à matéria orgânica podem ser superestimados, enfatizando que $\mathrm{Al}$ extraído com pirofosfato não pode ser atribuído unicamente à associação do elemento à fração húmica do solo, mas também à dissolução alcalina de gibbsita e à peptização de hidróxidos de $\mathrm{Al}$ associados à matéria orgânica neles adsorvida.

O objetivo desta pesquisa foi utilizar diferentes extratores a fim de investigar suas habilidades e especificidades na extração de formas de $\mathrm{Al}$ nos solos comumente encontrados nas restingas paulistas, com ênfase nos Espodossolos, e, com isso, caracterizá-los e inferir processos pedogenéticos e seus componentes mineralógicos. A abordagem consistiu em extrair e determinar o conteúdo de $\mathrm{Al}$ de amostras de solos com soluções rotineiramente utilizadas para fins de caracterização de horizontes espódicos e classificação dos Espodossolos, como DC, oxalato e pirofosfato. $\mathrm{NaOH} 0,5 \mathrm{~mol} \mathrm{~L}^{-1}$ em temperatura ambiente foi também utilizado e avaliado na extração de formas de $\mathrm{Al}$ inorgânico e complexado à matéria orgânica.

\section{MATERIAL E MÉTODOS}

Foram coletadas amostras de perfis de solos da planície costeira arenosa situada em três municípios do litoral do Estado de São Paulo: Bertioga, Cananeia (Ilha de Cananeia) e Ilha Comprida (Figura 1). O clima do litoral do Estado de São Paulo é do tipo Af, segundo a classificação climática de Köppen, com precipitação pluvial média anual de 1.800 a 2.000 mm e médias de temperaturas mínimas de $19^{\circ} \mathrm{C}$ e de temperaturas máximas de $27^{\circ} \mathrm{C}$ (Melo \& Mantovani, 1994). 


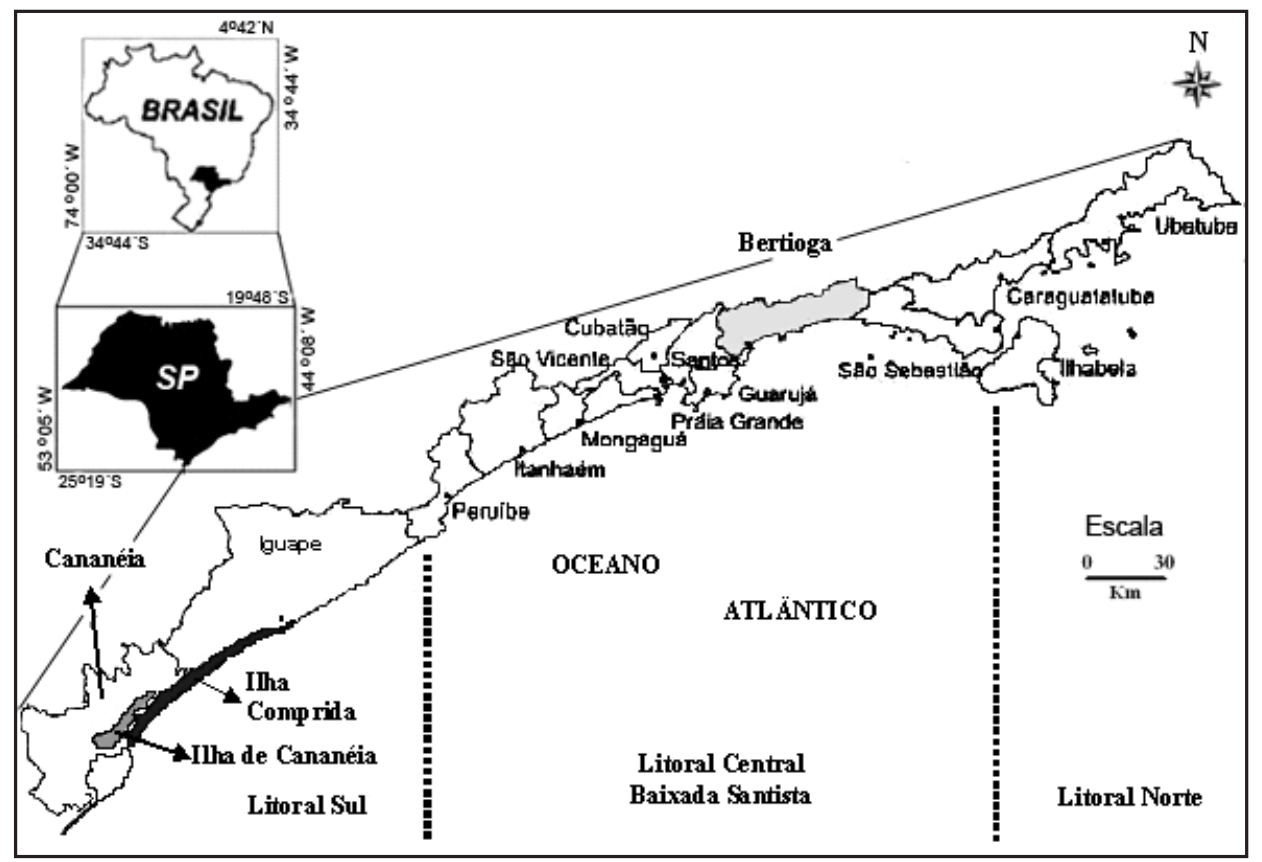

Figura 1. Localização dos municípios de Bertioga, Cananeia e Ilha Comprida no litoral do Estado de São Paulo.

A geologia dos locais estudados é composta por sedimentos arenosos quaternários de origem marinha (Petri \& Fúlfaro, 1970; Suguio \& Martin, 1978). Neles ocorre uma vegetação de floresta tropical úmida, genericamente denominada de restinga, característica das zonas costeiras (Suguio \& Tessler, 1984), cujos solos predominantes pertencem às classes dos Espodossolos e dos Neossolos Quartzarênicos (Oliveira et al., 1992) - esses últimos muitas vezes intermediários para Espodossolos (Gomes et al., 2007).

\section{Trabalhos de campo}

Os trabalhos de campo consistiram, inicialmente, em examinar os solos com o uso do trado, em barrancos e minitrincheiras, a fim de selecionar os locais de amostragem. Após os exames, foram selecionados os locais e abertos 31 perfis de solos representativos das paisagens locais. A localização dos perfis, a descrição morfológica e a classificação dos solos estudados são apresentadas por Coelho (2008). Vinte e sete perfis são Espodossolos e quatro foram classificados como Neossolos Quartzarênicos. Os perfis foram descritos e amostrados conforme Santos et al. (2005), e os solos, classificados segundo o Sistema Brasileiro de Classificação de Solos (Embrapa, 2006).

\section{Análises laboratoriais}

As amostras de solo foram secas ao ar, obtendo-se a fração terra fina seca ao ar, a qual foi utilizada para as análises químicas. $\mathrm{O} \mathrm{pH}$ foi determinado em água, utilizando relação solo:solução (peso) 1:2,5 após agitação e repouso de uma hora. O conteúdo de $\mathrm{C}$ orgânico (Corg) foi determinado por oxidação com dicromato de
K, segundo método proposto por Embrapa (1997); para C total (Ctotal) utilizou-se um analisador LECO CNH 1000. Houve bom ajuste das curvas entre Corg e Ctotal $(\mathrm{r}=0,96 ; \mathrm{p}<0,0001 ; \mathrm{n}=260)$. Devido às melhores correlações entre Corg e os demais dados aqui empregados, ele foi preferencialmente utilizado.

Foram adotados os seguintes procedimentos de dissolução seletiva para extração de Al e Fe: (a) extração com $\mathrm{NaOH}$ 0,5 mol L-1 $\left(\mathrm{Al}_{\mathrm{n}}\right)$ : relação solo:solução 1:100 e agitação por $16 \mathrm{~h}$. A suspensão foi centrifugada por 15 min a $2.500 \mathrm{rpm}$ após adição de quatro gotas de "suplerfoc" 0,2 \% (Borggaard, 1985). O sobrenadante foi filtrado através de papel-filtro lavado em ácido (7$11 \mu \mathrm{m}$ de diâmetro de poro); (b) extração com oxalato ácido de amônio de acordo com Buurman et al. (1996): relação solo:solução de 1:50, agitando por $4 \mathrm{~h}$ no escuro. A suspensão foi centrifugada por 15 min a $2.500 \mathrm{rpm}$, com quatro gotas de "superfloc", e o sobrenadante, filtrado como descrito anteriormente; (c) Extração com pirofosfato de sódio $0,1 \mathrm{~mol} \mathrm{~L}^{-1}$ (pH 10): relação solo:solução 1:100, agitando por $16 \mathrm{~h}$ (Buurman et al., 1996). Após adição de quatro gotas de "superfloc", procedeu-se à centrifugação e filtragem, conforme os procedimentos descritos anteriormente; (d) extração com ditionito-citrato de sódio (DC): relação solo: solução 1:125, agitando por $16 \mathrm{~h}$, segundo método proposto por Holmgren (1967). Os procedimentos seguintes foram semelhantes aos já relatados.

Alumínio e Fe nos extratos foram determinados por espectroscopia de absorção atômica. Os resultados obtidos para esses elementos representam a média das análises realizadas em duplicata, que diferiram entre si em menos que $10 \%$. 


\section{RESULTADOS E DISCUSSÃO}

\section{Relação entre extratores para todo o conjunto de amostras}

As diferentes formas de $\mathrm{Al}$ extraídas com $\mathrm{DC}$, oxalato, pirofosfato e hidróxido de sódio são correlacionadas entre si (Quadro 1). Verifica-se que Al extraído com oxalato ácido de amônio é o que melhor se correlaciona com os demais extratores, cujo maior coeficiente de correlação é observado com $\mathrm{NaOH}$ $0,5 \mathrm{~mol} \mathrm{~L}^{-1}$. Similares conteúdos extraídos por oxalato e NaOH também foram constatados tanto por Farmer et al. (1983), para horizontes espódicos Bs, como por García-Rodeja et al. (2004), para horizontes superficiais de Andosolos europeus, indicando, segundo esses autores, que os solos estudados apresentavam baixos teores de Al cristalino (García-Rodeja et al., 2004) e que uma fração reativa distinta foi removida pelos extratores (Farmer et al., 1983).

Uma vez que $\mathrm{NaOH}$ dissolve gibbsita, filossilicatos 1:1 de baixo grau de cristalinidade (Wada, 1980), bem como cristalinos (Kodama \& Ross, 1991), e considerando que tanto DC como pirofosfato e oxalato, juntamente com $\mathrm{NaOH} 0,5 \mathrm{~mol} \mathrm{~L}^{-1}$, têm sido mencionados dissolver complexos organometálicos dos solos (Wada, 1977), a boa correlação e proximidade dos valores de $\mathrm{Al}$ entre todos os extratores sugerem: (a) a dominância de $\mathrm{Al}$ na forma de complexos organometálicos em detrimento da presença do elemento na forma mineral (cristalina ou não), característico de Espodossolos e solos afins das áreas de restingas brasileiras (Gomes et al., 1998, 2007); e (b) a relativa especificidade dos extratores para Al, removendo a denominada fração reativa dos solos, como relatado por Farmer et al. (1983). No entanto, a figura 2 mostra que a reta da equação de regressão entre $\mathrm{Al}_{\mathrm{n}} \mathrm{e} \mathrm{Al}_{\mathrm{o}}$ ajusta-se próxima à da linha 1:1 e que os pontos que mais se afastam da reta situam-se abaixo da linha de regressão, sugerindo que formas minerais de $\mathrm{Al}$ também ocorrem em determinados

Quadro 1. Coeficientes de correlação linear do momento do produto Pearson para o conjunto de dados $(n=177)$ referentes ao $\mathrm{Al}$ extraído com $\mathrm{NaOH} 0,5 \mathrm{~mol} \mathrm{~L}^{-1}\left(\mathrm{Al}_{\mathrm{n}}\right)$, ditionito-citrato $\left(\mathrm{Al}_{\mathrm{d}}\right)$, oxalato ácido de amônio $\left(\mathrm{Al}_{\mathrm{o}}\right)$ e pirofosfato de sódio $\left(\mathrm{Al}_{\mathrm{p}}\right)(\mathrm{p}<0,0001)$

\begin{tabular}{ccccc}
\hline & \multicolumn{4}{c}{ Coeficiente de correlação } \\
\cline { 2 - 5 } Forma de Al & $\mathbf{A l}_{\mathbf{n}}$ & $\mathbf{A l}_{\mathbf{d}}$ & $\mathbf{A l}_{\mathbf{o}}$ & $\mathbf{A l}_{\mathbf{p}}$ \\
\hline & - & 0,86 & 0,97 & 0,90 \\
$\mathrm{Al}_{\mathbf{n}}$ & 0,86 & - & 0,93 & 0,93 \\
$\mathrm{Al}_{\mathrm{d}}$ & 0,97 & 0,93 & - & 0,93 \\
$\mathrm{Al}_{\mathrm{o}}$ & 0,90 & 0,93 & 0,93 & - \\
$\mathrm{Al}_{\mathbf{p}}$ & & & & \\
\hline
\end{tabular}

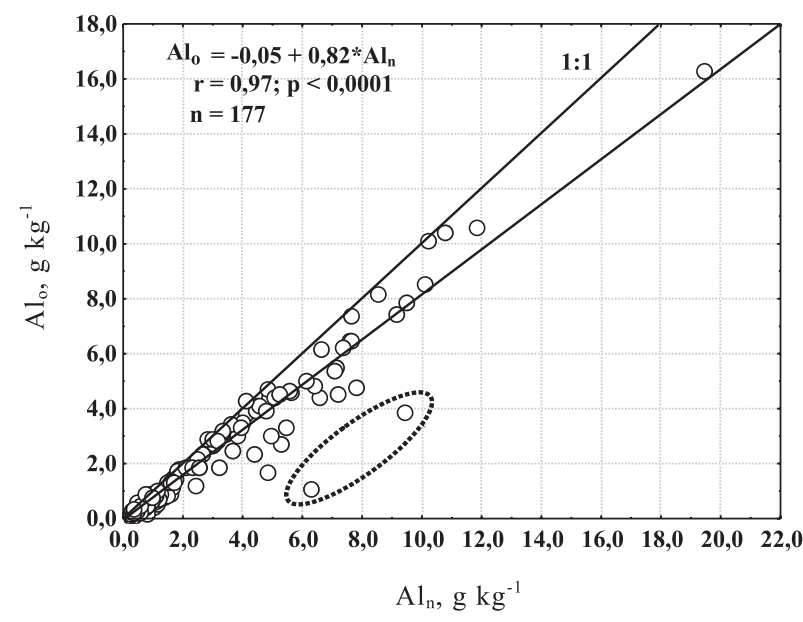

Figura 2. Relação entre o teor de Al extraído por $\mathrm{NaOH}\left(\mathrm{Al}_{\mathrm{n}}\right)$ e o por oxalato $\left(\mathrm{Al}_{\mathrm{o}}\right)$. Linha de regressão e equação para todas as amostras com valores de $\mathrm{Al}$ diferentes de zero. Eclipse circunda os pontos que mais se afastam da linha de regressão, situando-se abaixo dela. Isso sugere a presença de formas minerais de $\mathrm{Al}$ nos solos estudados. No entanto, formas orgânicas predominam.

horizontes e perfis estudados, o que será discutido posteriormente.

Lee et al. (1988), estudando Espodossolos da Flórida, constataram que $\mathrm{NaOH}$ dissolveu os maiores conteúdos de $\mathrm{Al}$, enquanto pirofosfato extraiu o menor, com valores intermediários para $\mathrm{Al}_{0}$. Esses autores atribuíram esses resultados ao fato de que $\mathrm{NaOH}$ pode dissolver gibbsita e outros constituintes minerais pouco cristalinos, enquanto pirofosfato é assumido ser específico para complexos organometálicos. Apenas parcialmente esses resultados são aqui reproduzidos.

Nos solos estudados, o $\mathrm{NaOH} 0,5 \mathrm{~mol} \mathrm{~L}^{-1}$ geralmente extraiu mais $\mathrm{Al}$ que os outros extratores, como constatado por Lee et al. (1988). Observa-se que $\mathrm{Al}_{n}$ aumenta com o aumento das diferenças entre $A l_{n}-A_{d}, A l_{n}-A l_{0}, A_{n}-A_{p}$ (Figura 3). $A_{o}, A_{d}$ e $A_{p}$ representam, em média, cerca de 78, 76 e $70 \%$, respectivamente do $\mathrm{Al}_{\mathrm{n}}$ (dados não mostrados).

A figura 4 mostra a correlação e a equação de regressão entre os conteúdos de $\mathrm{Al}$ extraídos por pirofosfato e aqueles extraídos com oxalato e DC de todos os horizontes e solos aqui estudados. A remoção de conteúdos similares entre os extratores já foi constatada anteriormente, bem como relatado por Gomes et al. (2007) para Espodossolos sob vegetação de restinga próxima às áreas estudadas. No entanto, os valores médios, mínimos e máximos da relação $\mathrm{Al}_{\mathrm{p}} /$ $\mathrm{Al}_{\mathrm{o}}$, respectivamente $0,91,0,24$ e 3,14, mostram que pirofosfato extrai mais que oxalato, e isso se deu para um número significativo de amostras (64, entre 177 amostras analisadas com relação $\mathrm{Al}_{\mathrm{p}} / \mathrm{Al}_{0}$ diferente de zero). Fato semelhante ocorre para a relação $\mathrm{Al}_{\mathrm{p}} / \mathrm{Al}_{\mathrm{d}}$ (valores médios, mínimos e máximos de 0,92, 0,02 e 


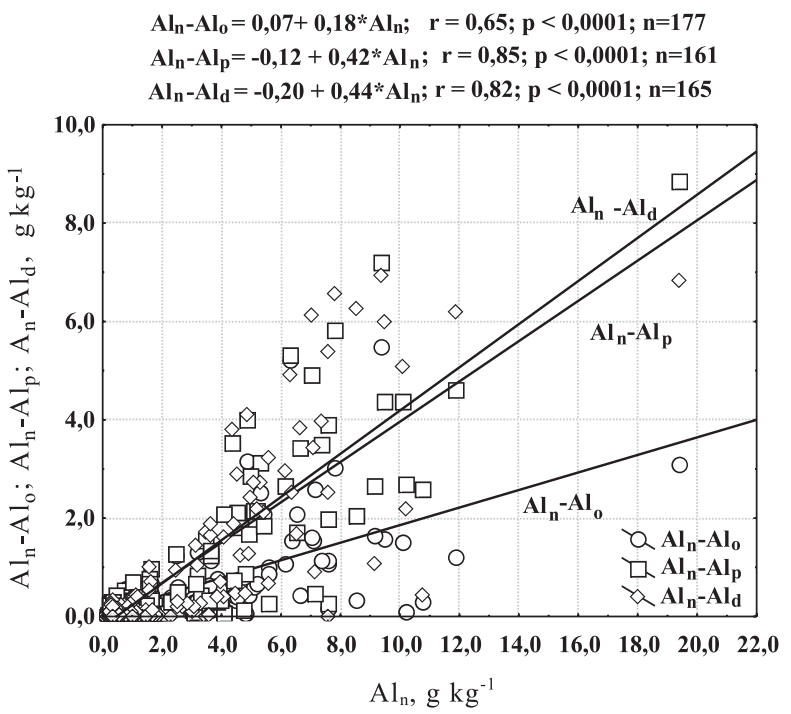

Figura 3. Relação entre o teor de $\mathrm{Al}$ extraído com $\mathrm{NaOH}\left(\mathrm{Al}_{\mathrm{n}}\right)$ e o de $\mathrm{Al}$ extraído por $\mathrm{NaOH}$, mas não por ditionito $\left(\mathrm{Al}_{\mathrm{n}}-\mathrm{Al}_{\mathrm{d}}\right)$, oxalato $\left(\mathrm{Al}_{\mathrm{n}}-\mathrm{Al}_{\mathrm{o}}\right)$ e pirofosfato $\left(\mathrm{Al}_{\mathrm{n}}-\mathrm{Al}_{\mathrm{p}}\right)$. Foram incluídos apenas horizontes com valores de $\mathrm{Al}$ diferentes de zero e aqueles com diferença positiva ou nula entre os extratores.

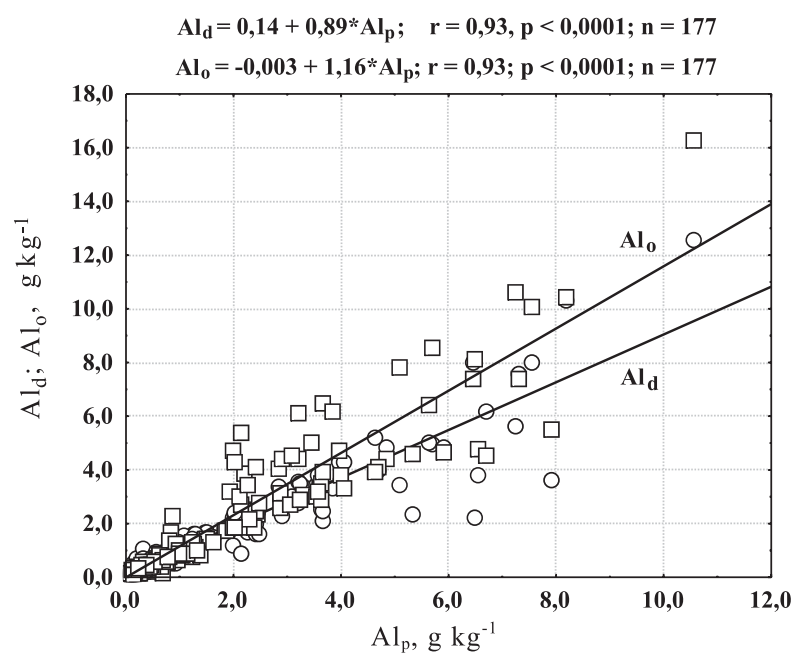

Figura 4. Relação entre os extratores DC, pirofosfato e oxalato para todos os horizontes dos perfis analisados.

2,90, respectivamente). Esses resultados sugerem falta de especificidade dos extratores para $\mathrm{Al}$ : seja do pirofosfato para formas do elemento unicamente associadas à matéria orgânica, as quais podem incluir óxidos (Soon, 1993), tal como relatado por vários autores (Bascomb, 1968; Higashi et al., 1981; McKeague \& Schuppli, 1982; Soon, 1993; Kaiser \& Zech, 1996; Sauer et al., 2007), seja do oxalato (Iyengar et al., 1981; Shoji \& Fujiwara, 1984; Farmer et al., 1988; Skjemstad et al., 1992a) ou ditionito (Farmer et al., 1983; García-Rodeja et al., 2004).

\section{Relação entre extratores para os horizontes espódicos}

Os baixos valores de $\mathrm{pH}$ em água dos horizontes $\mathrm{B}$ espódicos (dados não mostrados), com valores médios, mínimos e máximos de 4,5, 3,1 e 6,0, respectivamente, encontram-se, em média, abaixo daqueles mínimos considerados adequados à formação de alofana e imogolita - condições ácidas essas favoráveis à dominância de complexos Al-húmus em detrimento de compostos inorgânicos pouco cristalinos (Shoji et al., 1982; Shoji \& Fujiwara, 1984). García-Rodeja et al. (2004) comentam que em valores de $\mathrm{pH}<4,9$ a complexação do $\mathrm{Al}$ pela matéria orgânica exerce efeito antialofânico, não deixando $\mathrm{Al}$ disponível para formar alofana e imogolita. No entanto, o pH máximo $(6,0)$ e a observação de alguns horizontes Bs, Bhs, Bsm e Bh selecionados (Quadro 2), cujos valores de $\mathrm{pH}$ se aproximam ou mesmo extrapolam 4,9 , aliado às suas relações $\mathrm{Al}_{\mathrm{o}} / \mathrm{Al}_{\mathrm{d}}$ e $\mathrm{Al}_{\mathrm{p}} / \mathrm{Al}_{0}$, sugerem que as condições químicas são favoráveis e houve formação de silicatos pouco cristalinos nesses horizontes espódicos, os quais se encontram nas porções inferiores de perfis bem drenados. Nesses horizontes, a relação $\mathrm{Al}_{\mathrm{p}} / \mathrm{Al}_{\mathrm{o}}$ foi sempre inferior a uma unidade, com valores mínimos e máximos de 0,34 e 0,92 (Quadro 2), respectivamente, estando entre os menores observados em um mesmo perfil (dados não mostrados). Ao contrário, $\mathrm{Al}_{\mathrm{o}} / \mathrm{Al}_{\mathrm{d}}$ situou-se acima de uma unidade para os mesmos horizontes (Quadro 2).

Relações semelhantes às descritas foram observadas por Farmer et al. (1983) para horizonte Bs e por Childs et al. (1983) para horizontes Bh e Bs de Espodossolos boreais cuja fração argila continha alofana e imogolita. Para esses autores, essas relações ocorrem pelo fato de o oxalato ser mais efetivo na extração de formas inorgânicas pouco cristalinas de $\mathrm{Fe}, \mathrm{Al}$ e Si nos horizontes espódicos, ao passo que o pirofosfato é mais seletivo para complexos orgânicos e remove pequenos conteúdos de Fe, Al e Si dos solos. Por outro lado, DC dissolve eficientemente óxidos de Fe livre, mas extrai, apenas parcialmente, alofana e imogolita (Farmer et al., 1983; Shoji \& Fujiwara, 1984) e outros silicatos pouco cristalinos; daí as relações $\mathrm{Al}_{\mathrm{p}} / \mathrm{Al}_{\mathrm{o}}<1$ e $\mathrm{Al}_{\mathrm{o}}$ / $\mathrm{Al}_{\mathrm{d}}>1$ em alguns horizontes dos Espodossolos aqui estudados e naqueles relatados por Childs et al. (1983) e Farmer et al. (1983) serem indicativas da presença de amorfos inorgânicos de $\mathrm{Al}$.

Outros fatores, no entanto, devem ser considerados na avaliação da mineralogia, com enfoque na presença de silicatos pouco cristalinos quando se utilizam dissoluções seletivas. Apesar de as relações $\mathrm{Al}_{\mathrm{p}} / \mathrm{Al}_{\mathrm{o}} \mathrm{e}$ $\mathrm{Al}_{\mathrm{o}} / \mathrm{Al}_{\mathrm{d}}$ utilizadas terem sido semelhantes às descritas para Espodossolos de clima frio (Childs et al., 1983; Farmer et al., 1983) nos valores de $\mathrm{pH}$ relatados $(\mathrm{pH}>4,9)$, essas informações podem sugerir a presença desses minerais, mas não os caracterizam de forma definitiva.

A presença de gibbsita e, ou, sobretudo, de caulinita, ambas com baixo grau de cristalinidade nesses 
Quadro 2. Dados químicos referentes a horizontes espódicos selecionados (Bs, Bh, Bhs e Bsm)

\begin{tabular}{|c|c|c|c|c|c|c|c|c|c|c|c|c|c|}
\hline Perfil & Hor. ${ }^{(1)}$ & Prof. $^{(2)}$ & pH & Ctotal $^{(3)}$ & Corg $^{(4)}$ & $\mathrm{Al}_{\mathrm{p}}^{(5)}$ & $\mathrm{Al}_{\mathrm{n}}^{(6)}$ & $\left(\mathrm{Al}_{\mathrm{n}} \mathrm{Al}_{\mathrm{o}}\right)^{(7)}$ & $\left(\mathrm{Al}_{\mathrm{n}-\mathrm{Al}}-\mathrm{Al}_{\mathrm{d}}\right)^{(8)}$ & $\left(\mathrm{Al}_{\sigma}-\mathrm{Al}_{\mathrm{p}}\right)^{(9)}$ & $\frac{\mathrm{Al}_{\mathrm{o}}}{\mathrm{Al}_{\mathrm{d}}^{(10)}}$ & $\frac{\mathrm{Al}_{\mathrm{p}}}{\mathrm{Al}_{\mathrm{o}}{ }^{(11)}}$ & $\frac{\mathrm{Al}_{\mathrm{p}}+\mathrm{Fe}_{\mathrm{p}}}{\mathrm{Corg}}$ \\
\hline 2 & Bhs2 & $74-116$ & 4,9 & 9,90 & 9,76 & 3,65 & 4,40 & 0,45 & 1,89 & 0,31 & 1,58 & 0,92 & 0,78 \\
\hline 2 & Bhs5 & $128-153$ & 5,1 & 4,76 & 4,41 & 2,25 & 3,60 & 0,13 & 1,89 & 1,22 & 2,03 & 0,65 & 0,79 \\
\hline 2 & Bhs6 & $126-152$ & 5,2 & 6,10 & 6,30 & 2,88 & 5,05 & 0,62 & 2,74 & 1,56 & 1,92 & 0,65 & 0,70 \\
\hline 2 & Bhs7 & $140-200$ & 5,3 & 5,51 & 4,41 & 2,40 & 4,52 & 0,40 & 2,90 & 1,73 & 2,55 & 0,58 & 0,74 \\
\hline 3 & Bs2 & $125-180$ & 5,2 & 4,40 & 4,24 & 1,91 & 3,47 & 0,26 & 1,71 & 1,31 & 1,83 & 0,59 & 0,47 \\
\hline 3 & Bsm2 & $153-180$ & 5,2 & 9,11 & 8,18 & 3,20 & 6,63 & 0,46 & 3,83 & 2,98 & 2,20 & 0,52 & 0,39 \\
\hline 4 & $\mathrm{Bs}$ & $130-160$ & 4,9 & 5,35 & 5,47 & 0,78 & 1,57 & 0,19 & 0,53 & 0,61 & 1,33 & 0,56 & 0,18 \\
\hline 5 & Bs1 & 78-101 & 4,7 & 13,92 & 12,59 & 5,69 & 10,08 & 1,51 & 5,10 & 2,89 & 1,72 & 0,66 & 0,91 \\
\hline 5 & Bs2 & $82-85$ & 4,8 & 6,26 & 5,35 & 3,65 & 7,56 & 1,08 & 5,40 & 2,84 & 3,00 & 0,56 & 0,75 \\
\hline 5 & Bs3 & $95-126$ & 4,6 & 12,15 & 10,07 & 5,07 & 9,45 & 1,59 & 5,98 & 2,79 & 2,27 & 0,65 & 0,83 \\
\hline 5 & Bs5 & $130-150$ & 4,8 & 5,22 & 3,15 & 1,98 & 7,81 & 2,04 & 6,57 & 2,79 & 4,67 & 0,34 & 0,72 \\
\hline 5 & Bs7 & $155-180$ & 4,7 & 15,28 & 13,85 & 7,23 & 11,84 & 1,22 & 6,21 & 3,39 & 1,89 & 0,68 & 0,58 \\
\hline 17 & Bs & $243-485$ & 5,0 & 4,98 & 4,48 & 0,36 & 0,55 & 0,04 & 0,04 & 0,15 & 1,02 & 0,70 & 0,08 \\
\hline 19 & Bh1 & $68-105$ & 5,3 & 6,89 & 6,82 & 0,25 & 0,54 & 0,15 & 0,25 & 0,15 & 1,37 & 0,62 & 0,04 \\
\hline 19 & Bh2 & $105-117$ & 4,8 & 7,66 & 8,37 & 0,28 & 0,61 & 0,15 & 0,24 & 0,19 & 1,24 & 0,61 & 0,03 \\
\hline 28 & Bhs4 & $77-177$ & 5,1 & 10,40 & 10,81 & 5,63 & 7,60 & 1,14 & 2,54 & 0,84 & 1,28 & 0,87 & 0,88 \\
\hline 28 & Bhs5 & $111-200$ & 5,1 & 6,57 & 6,33 & 3,06 & 5,20 & 0,66 & 2,17 & 1,48 & 1,50 & 0,67 & 0,66 \\
\hline 28 & Bhs6 & $134-160$ & 4,9 & 9,00 & 8,49 & 3,84 & 7,35 & 1,13 & 3,99 & 2,38 & 1,85 & 0,62 & 0,65 \\
\hline 28 & Bhs7 & $150-200$ & 5,0 & 7,27 & 6,79 & 3,44 & 6,11 & 1,07 & 2,98 & 1,60 & 1,61 & 0,68 & 1,03 \\
\hline
\end{tabular}

(1) Hor. = horizonte. ${ }^{(2)}$ Prof.: profundidade. ${ }^{(3)}$ Ctotal: carbono total. ${ }^{(4)}$ Corg: carbono orgânico. ${ }^{(5)} \mathrm{Al}_{\mathrm{p}}$ : $\mathrm{Al}$ extraído com pirofosfato. (6) $\mathrm{Al}_{\mathrm{n}}$ : $\mathrm{Al}$ extraído com $\mathrm{NaOH} \mathrm{0,5} \mathrm{mol} \mathrm{L-1.(7)}\left(\mathrm{Al}_{\mathrm{n}}-\mathrm{Al}_{\mathrm{o}}\right)$ : Al especificamente extraído por $\mathrm{NaOH} \mathrm{0,5} \mathrm{mol} \mathrm{L-1}\left(\mathrm{Al}_{\mathrm{n}}\right)$, mas não por oxalato $\left(\mathrm{Al}_{\mathrm{o}}\right) ; \mathrm{Al}$ cristalino ou menos reativo. ${ }^{(8)}\left(\mathrm{Al}_{\mathrm{n}}-\mathrm{Al}_{\mathrm{d}}\right)$ : $\mathrm{Al}$ especificamente extraído por $\mathrm{NaOH} 0,5 \mathrm{~mol} \mathrm{~L}^{-1}\left(\mathrm{Al}_{\mathrm{n}}\right)$, mas não por ditionitocitrato $\left(\mathrm{Al}_{\mathrm{d}}\right){ }^{(9)}\left(\mathrm{Al}_{\mathrm{o}}-\mathrm{Al}_{\mathrm{p}}\right)$ : $\mathrm{Al}$ especificamente extraído por oxalato $\left(\mathrm{Al}_{\mathrm{o}}\right)$, mas não por pirosfato $\left(\mathrm{Al}_{\mathrm{p}}\right)$; $\mathrm{Al}$ presente na estrutura dos aluminossilicatos amorfos. ${ }^{(10)} \mathrm{Al}_{\mathrm{o}} / \mathrm{Al}_{\mathrm{d}}$ : relação entre o $\mathrm{Al}$ extraído por oxalato $\left(\mathrm{Al}_{\mathrm{o}}\right)$ e o $\mathrm{Al}$ extraído por ditionito-citrato $\left(\mathrm{Al}_{\mathrm{d}}\right)$. ${ }^{(11)} \mathrm{Al}_{\mathrm{p}} / \mathrm{Al}_{\mathrm{o}}$ : relação entre $\mathrm{Al}$ extraído por pirofosfato $\left(\mathrm{Al}_{\mathrm{p}}\right)$ e $\mathrm{Al}$ extraído por oxalato $\left(\mathrm{Al}_{\mathrm{o}}\right){ }^{(12)} \mathrm{Al}_{\mathrm{p}}+\mathrm{Fe}_{\mathrm{p}} /$ Corg: relação entre $\mathrm{Al}+\mathrm{Fe}$ extraídos com pirofosfato $\left(\mathrm{Al}_{\mathrm{p}}+\mathrm{Fe}_{\mathrm{p}}\right)$ e carbono orgânico (Corg).

horizontes, é mais provável em função das referidas relações entre extratores nos valores de $\mathrm{pH}$ encontrados no quadro 2, o que vai ao encontro: (a) da reconhecida capacidade de extração dos reagentes utilizados (Parfitt \& Childs, 1988; Kodama \& Ross, 1991); (b) da relativa pobreza do material de partida (van Breemen \& Buurman, 2002) dos solos estudados; e (c) dos processos de formação dos Espodossolos nas condições químicas aqui encontradas, como relatado por Farmer et al. (1983). Esses autores argumentam que sob condições ácidas em que os Espodossolos são formados é plausível a mobilidade do $\mathrm{Al}$ como íons $\mathrm{Al}^{3+}$ e $\mathrm{Al}(\mathrm{OH})^{2+}$, especialmente em materiais de origem pobres, onde silicatos são insuficientes para formar protoimogolita, precursor da imogolita. Os autores complementam que $\mathrm{Al}$ pode mover-se verticalmente nessas condições e precipitar nos horizontes mais profundos devido aos valores mais elevados de $\mathrm{pH}$, como ocorre nos horizontes $\mathrm{Bs}$, Bhs e Bsm aqui estudados (Quadro 2) e, sobretudo, nos horizontes C (dados não mostrados), originando gibbsita mal cristalizada.

A significativa diferença entre o $\mathrm{Al}_{n}$ e o $\mathrm{Al}_{d}\left(\mathrm{Al}_{n}\right.$ $\mathrm{Al}_{\mathrm{d}}$ ) observada no quadro 2 , as quais estão entre as maiores verificadas nos respectivos perfis (dados não mostrados), sugere a presença de gibbsita e, ou, caulinita, uma vez que DC falha na dissolução de aluminossilicatos não cristalinos ou gibbsita (Dalhgren \& Saigusa, 1994), enquanto $\mathrm{NaOH} 0,5 \mathrm{~mol} \mathrm{~L}^{-1}$ reconhecidamente dissolve gibbsita e aluminossilicatos pouco cristalinos (Darke \& Walbridge, 1994).

Oxalato, no entanto, é comumente utilizado para dissolver hidróxidos e oxidróxidos de $\mathrm{Al}$ de baixo grau de cristalinidade (McKeague \& Day, 1966; McKeague et al., 1971), além de alguma gibbsita (Parfitt \& Childs, 1988; Kodama \& Ross, 1991); daí os valores positivos da diferença entre $\mathrm{Al}_{n}$ e $\mathrm{Al}_{\mathrm{o}}\left(\mathrm{Al}_{\mathrm{n}}-\mathrm{Al}_{\mathrm{o}}\right)$ (Quadro 2), indicando que formas de $\mathrm{Al}$ cristalino ou menos reativo (García-Rodeja et al., 2004) podem estar presentes em alguns horizontes espódicos bem drenados, sobretudo naqueles identificados como Bs do perfil P5, os quais mostram o maior valor da diferença entre os extratores oxalato e $\mathrm{NaOH}$ 0,5 $\mathrm{mol} \mathrm{L}^{-1}$ (Quadro 2). Contudo, as formas pouco cristalinas do elemento predominam.

Devido à evidente presença das formas inorgânicas de $\mathrm{Al}$ e à relativa especificidade dos extratores supracitados, outras relações e considerações podem ser mencionadas com respeito aos horizontes espódicos elencados no quadro 2: (a) a curva de regressão $(r=$ 0,99; $\mathrm{p}<0,0001$ ) entre $\mathrm{Al}_{\mathrm{n}}$ e $\mathrm{Al}_{\mathrm{o}}$ para esse conjunto de horizontes é mais bem ajustada, seja em relação àquela que considera todos os horizontes e perfis aqui estudados $(r=0,97 ; p<0,0001)$, seja analisando apenas os horizontes espódicos $(r=0,98$; $p<0,0001$; dados não mostrados); e (b) a diferença $\mathrm{Al}_{\mathrm{o}}-\mathrm{Al}_{\mathrm{p}}$ 
(Quadro 2), a qual se refere ao $\mathrm{Al}$ presente na estrutura dos aluminossilicatos amorfos (McKeague \& Day, 1966), segue a mesma tendência da relatada para a diferença entre $\mathrm{Al}_{n} \mathrm{eAl}_{\mathrm{d}}$, ou seja, está entre as maiores observadas entre os demais horizontes dos respectivos perfis (dados não mostrados). Ambas as diferenças $\left(\mathrm{Al}_{\mathrm{n}}-\mathrm{Al}_{\mathrm{d}}\right.$ e $\mathrm{Al}_{\mathrm{o}}-\mathrm{Al}_{\mathrm{p}}$; Quadro 2), sempre positivas, e suas magnitudes, bem como as relações entre extratores, discriminam tais horizontes bem drenados (Bs, Bhs, Bh e Bsm) dos demais morfologicamente distintos e sujeitos a condições hidromórficas diferenciadas (A, $\mathrm{Bhm}, \mathrm{C}$ e a grande maioria dos horizontes $\mathrm{Bh}$ mal drenados). Além disso, essas informações fornecem indicações da composição mineralógica e dos processos envolvidos na formação dos Espodossolos sob vegetação de restinga, condizentes com a literatura mundial sobre o tema e com a habilidade extratora dos reagentes utilizados.

A abordagem aqui adotada, analisando-se preliminarmente todos os horizontes e perfis e, posteriormente, restringindo a forma de análise a um conjunto menor de amostras de horizontes com características diferenciadas morfologicamente, que foram discriminadas pelas técnicas de dissoluções seletivas, comprovam a relativa habilidade e especificidade dos reagentes $\mathrm{NaOH}, \mathrm{DC}$, oxalato e pirofosfato em extrair as diferentes formas de $\mathrm{Al}$ dos Espodossolos estudados. Se houve alguma ineficiência dos extratores para formas de $\mathrm{Al}$ em alguns horizontes ou perfis, esta, possivelmente, não será limitante a ponto de inviabilizar ou incorrer em interpretações enganosas na sua utilização para fins de caracterização química e em estudos de pedogênese dos solos das áreas de restinga, sobretudo quanto ao pirofosfato. A especificidade deste extrator pode ser confirmada pelo exame da figura 5 a. Esta foi obtida utilizando-se os dados do quadro 2: a curva designada de Ap1 (Figura 5a) refere-se a todo o conjunto de dados do referido quadro; e Ap2, aos mesmos conjuntos, eliminando-se os quatro menores valores do extrato pirofosfato.

A primeira e forte evidência da capacidade do pirofosfato em extrair $\mathrm{Al}$ organicamente unido vem da boa relação obtida entre $\mathrm{Al}_{\mathrm{p}}$ e Corg. Utilizando-se todos os dados do quadro 2, a curva Ap1 (Figura 5a) apresenta pior ajuste em relação aos dados selecionados, curva Ap2. Essa seleção compreende os mais baixos valores de $\mathrm{Al}_{\mathrm{p}}$ e da relação $\mathrm{Al}_{\mathrm{p}}+\mathrm{Fe}_{\mathrm{p}} / \mathrm{C}$ (Quadro 2), que não acompanharam o aumento do conteúdo do Corg, ou seja, para três dessas amostras, aumentando-se o conteúdo de Corg não há aumento da capacidade de extração do pirofosfato. Apesar dos pequenos conteúdo e amplitude de variação do Corg das amostras, com valores similares ao do $\mathrm{C}$ total (Ctotal; Quadro 2), a tendência relatada pode indicar que a influência da matéria orgânica nesses horizontes não depende unicamente da quantidade, mas também de sua natureza, como demonstrado por vários autores (Higashi et al., 1981; Buurman 1985; Dahlgren \& Saigusa, 1994; Urrutia et al., 1995). As diferentes substâncias húmicas, ácidos húmicos, fúlvicos e humina, por exemplo, apresentam diferentes capacidades de retenção de metais (Stevenson, 1982; Skjemstad, 1992).

A interpretação sobre a natureza diferenciada do húmus e das condições químicas locais que definem as diferentes formas de $\mathrm{Al}$ nos solos também pode explicar a grande dispersão dos dados quando se analisa a relação entre $\mathrm{Al}_{\mathrm{p}}$ e Corg de todos os perfis e horizontes estudados (ampla variação do Corg e $\mathrm{Al}_{\mathrm{p}}$ ), bem como ao se restringir a análise aos horizontes espódicos, como observado na figura 6. Nesta, verificam-se os baixos conteúdo e saturação por $\mathrm{Al}$ no húmus para muitos horizontes superficiais $\mathrm{A}$ (amostras circundadas), uma vez que há variação e aumento expressivo do Corg $\left(15<\operatorname{Corg}<80 \mathrm{~g} \mathrm{~kg}^{-1}\right)$ com pequeno ou nulo incremento no conteúdo de $\mathrm{Al}_{\mathrm{p}}$ $\left(0,1<\mathrm{Al}_{\mathrm{p}}<0,4 \mathrm{~g} \mathrm{~kg}^{-1}\right)$, semelhante ao descrito para os horizontes espódicos bem drenados da figura 5a.

De fato, Wada \& Higashi (1976), ao utilizarem procedimentos de dissoluções seletivas, constataram que o horizonte A de Andossolos, também caracterizados pela presença de complexos Al-húmus (Shoji \& Fujiwara, 1984), mostrou baixa capacidade de complexação de metais devido à presença de matéria orgânica jovem. Para o caso dos horizontes espódicos, essa matéria orgânica mais jovem pode estar presente em alguns horizontes e perfis estudados, sobretudo naqueles bem drenados e que recebem material orgânico iluvial fresco de forma contínua. Em alguns desses horizontes, com baixos conteúdos de Corg $\left(<15 \mathrm{~g} \mathrm{~kg}^{-1}\right)$, como observado anteriormente, os valores de $\mathrm{pH}$ e as relações entre extratores (Quadro 2; Figura 5a) indicaram a ocorrência de materiais inorgânicos de $\mathrm{Al}$ pouco cristalinos, evidenciando a formação preferencial de tais compostos em detrimento da complexação do $\mathrm{Al}$ pelo húmus; daí a falta ou pequena relação entre Corg e $\mathrm{Al}_{\mathrm{p}}$ para algumas amostras da figura $5 \mathrm{a}$ (circundadas), possivelmente com natureza diferenciada dos componentes orgânicos em relação aos demais horizontes. De fato, a matéria orgânica desses horizontes (amostras circundadas; Figura 5a) não parece estar saturada com metais. Os valores da relação $\mathrm{Al}_{\mathrm{p}}+\mathrm{Fe}_{\mathrm{p}} / \mathrm{Corg}$ (relação Metal/Corg) do quadro 2 dessas mesmas amostras (perfis 18 e 26) encontram-se muito abaixo ou próximos a 0,12 e são os menores observados - valor este considerado por Higashi et al. (1981) como limite para a união de metais à matéria orgânica do solo. Isso novamente corrobora os resultados e discussões anteriores de que as condições químicas em alguns horizontes espódicos bem drenados são favoráveis às formas de $\mathrm{Al}$ inorgânico, mas sugere, para a maioria das amostras e com relação metal/Corg muito superior a 0,12 , que o pirofosfato pode ter extraído outras formas que não apenas $\mathrm{Al}$ complexado à matéria orgânica.

$\mathrm{Na}$ figura 5b,c é mostrada, respectivamente, a relação entre o Corg e o $\mathrm{Al}$ presente na estrutura dos minerais amorfos $\left(\mathrm{Al}_{0}-\mathrm{Al}_{\mathrm{p}}\right)$ e cristalinos $\left(\mathrm{Al}_{\mathrm{n}}-\mathrm{Al}_{\mathrm{o}}\right)$. 

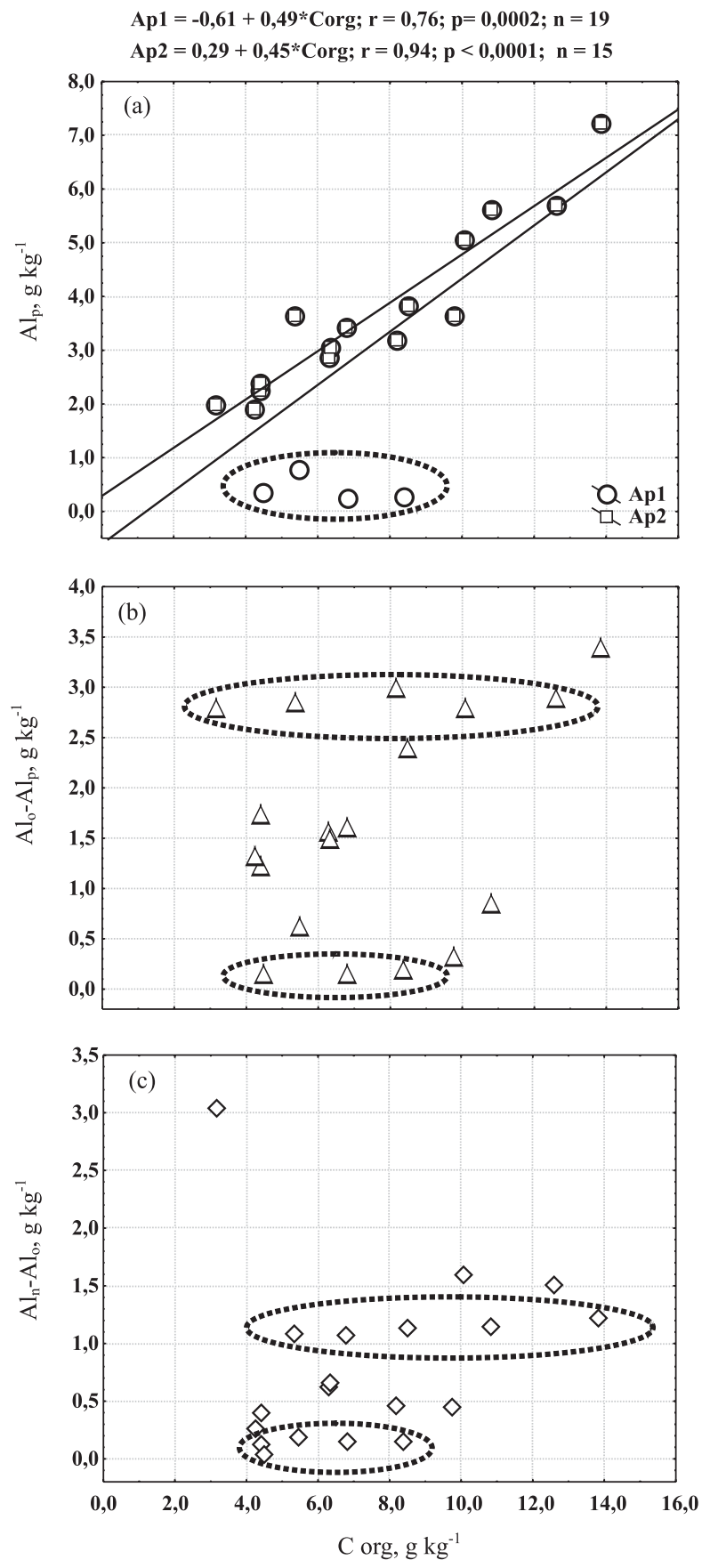

Figura 5. Relação entre o teor de carbono orgânico (Corg) e o de (a) Al extraído com pirofosfato $\left(\mathrm{Al}_{\mathrm{p}}\right)$. Ap1 refere-se a todo o conjunto de amostras do quadro 2; Ap2 são as mesmas amostras, eliminando-se aquelas circundadas pela elipse; (b) Al presente na estrutura dos aluminossilicatos amorfos $\left(\mathrm{Al}_{\mathrm{o}}-\mathrm{Al}_{\mathrm{p}}\right)$; (c) $\mathrm{Al}$ cristalino ou menos reativo $\left(\mathrm{Al}_{\mathrm{n}}-\mathrm{Al}_{\mathrm{o}}\right)$.

Embora haja tendência de aumento do teor de $\mathrm{Al}$ amorfo com o teor de Corg (Figura 5b), essa é pouco expressiva, conforme pode ser verificado pela grande dispersão dos dados $(r=0,30)$. Observa-se que praticamente não há relação entre o teor de Corg e minerais cristalinos $(r=0,18)$ (Figura 5c). As amostras circundadas nas figuras evidenciam que o aumento do teor de Corg não é acompanhado pelo aumento significativo das formas de $\mathrm{Al}$ no solo. Esses resultados comprovam a habilidade e relativa especificidade dos extratores para extrair as diferentes formas de $\mathrm{Al}$, pois, caso contrário, esperar-se-ia melhor ajuste das curvas, como ocorreu na figura 5a (relação entre Corg e $\mathrm{Al}_{\mathrm{p}}$ ).

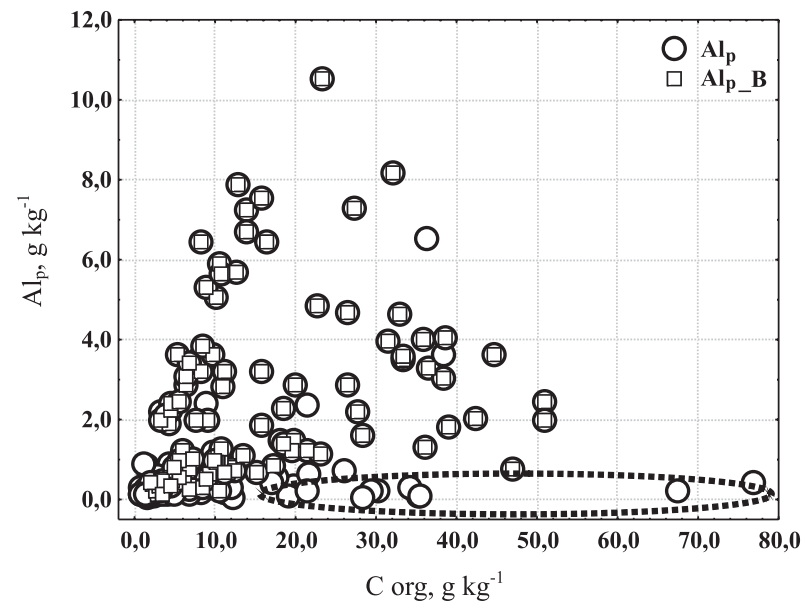

Figura 6. Relação entre o teor de carbono orgânico (Corg) e o de $\mathrm{Al}$ extraído por pirofosfato $\left(\mathrm{Al}_{\mathrm{p}}\right)$. As amostras designadas de $\mathrm{Al}_{\mathrm{p}}$ referem-se à relação entre Corg e $\mathrm{Al}_{\mathrm{p}}$ de todos os horizontes aqui estudados (horizontes A, E, B, C e intermediários), com valores diferentes de zero. $A_{p}-B h$ refere-se à relação entre o Corg e o conjunto de dados dos horizontes espódicos. Elipse circunda alguns horizontes superficiais do tipo A que apresentaram baixos conteúdos de $\mathrm{Al}_{\mathrm{p}}$ e que pouco variaram com o aumento do Corg.

\section{CONSIDERAÇÕES FINAIS}

A significativa dispersão dos dados mostrados na figura 6 deve refletir, em grande parte, a complexidade da matéria orgânica (grau de humificação e química) e as condições pedogenéticas nas quais os horizontes e perfis são formados, ao contrário da relativa falta de especificidade do reagente pirofosfato para formas de Al associados à matéria orgânica, conforme se observou ao analisar um menor conjunto de dados (Quadro 2; Figura 5). A visível e contrastante diversidade morfológica (cor e consistência), bem como a variabilidade espacial dos horizontes (A, E, EA, AE, Bs, Bh, Bhg, Bhm, Bsm, Bhs, CB e C) dos solos verificada em campo, tanto horizontal como vertical (Coelho et al., 2010), sugerem que compostos orgânicos e inorgânicos também variam e são corresponsáveis por essa diversidade. De fato, a natureza diferenciada do húmus nos Espodossolos, sobretudo dos horizontes espódicos, tem sido uma constante na literatura que aborda o tema em ambientes tropicais (Gomes et al., 
1988; Skjemstad et al., 1992a,b; van Ranst et al., 1997; Gonzáles-Pérez et al., 2008).

$\mathrm{O}$ uso de extratores para determinar formas específicas de ocorrência de metais nos solos tem um número de deficiências, particularmente onde a química é tão complexa como a do Al. Extratores podem reagir com formas outras que aquelas esperadas, e os metais podem mudar sua forma durante a extração e mesmo não permanecer em solução (Jarvis, 1986). Para o caso do pirofosfato, se o extrato de algumas amostras aqui analisadas, sobretudo daquelas referentes aos horizontes espódicos bem drenados, contém materiais outros que $\mathrm{Al}$ complexado à matéria orgânica, isso deve ser considerado na avaliação do elemento como critério na distinção de horizontes espódicos. No entanto, como afirmam McKeague \& Schuppli (1982), se tal critério resulta numa consistente e lógica diferenciação dos solos e horizontes, demonstrando-se relevantes tendências e relações na interpretação dos resultados das análises, como observado neste trabalho, as consequências negativas de utilizar essas informações são pouco relevantes.

Devido à carência de estudos mineralógicos nesses solos sob condições tropicais, sugere-se uma avaliação detalhada da mineralogia da exígua fração argila de seus horizontes, o que contribuirá para a caracterização com ênfase no entendimento dos processos de podzolização nesses ambientes frágeis e pouco estudados de restinga. Ademais, esses estudos darão suporte ao aperfeiçoamento da classe dos Espodossolos no SiBCS, uma das mais carentes em atributos químicos discriminadores de classes, principalmente em nível de ordem taxonômica.

\section{CONCLUSÕES}

1. As formas predominantes de $\mathrm{Al}$ ativo nos Espodossolos estudados são: complexos de $\mathrm{Al}$-húmus e compostos inorgânicos pouco cristalinos. Enquanto os primeiros predominam nos horizontes superficiais (A e intermediários) e horizontes espódicos hidromórficos (Bh e Bhm), as formas inorgânicas amorfas se relacionam predominantemente a alguns horizontes espódicos bem drenados (Bs, Bh, Bhs e Bsm), situados na base dos perfis.

2. $\mathrm{NaOH} 0,5 \mathrm{~mol} \mathrm{~L}^{-1}$ extraiu, em média, 22 a $30 \%$ mais $\mathrm{Al}$ que os outros extratores e, juntamente com DC, oxalato, pirofosfato e suas relações, discriminaram perfeitamente alguns horizontes espódicos bem drenados (Bs, Bh, Bhs e Bsm) daqueles em que os complexos Al-húmus são únicos ou predominam. Nesses, todos os extratores tiveram eficácia semelhante.

3. Ditionito-citrato foi menos efetivo na extração de $\mathrm{Al}$ do que o oxalato e pirofosfato nos mesmos horizontes espódicos bem drenados relatados devido à inabilidade dele na extração de componentes inorgânicos de $\mathrm{Al}$ pouco cristalinos.

4. Apesar de insuficientes e não definitivos, os valores de $\mathrm{pH}$ associados à relação entre os extratores aqui utilizados condizem com a presença de minerais do tipo alofana, gibbsita ou caulinita em alguns horizontes espódicos bem drenados. Os primeiros são frequentes apenas em Espodossolos boreais e temperados.

\section{AGRADECIMENTOS}

À CAPES, pelo financiamento do doutoradosanduíche do primeiro autor concedido pelo convênio CAPES/MECD-DGU; à FAPESP, por meio do projeto "Solos sob vegetação de restinga no Estado de São Paulo: relações solo-paisagem, pedogênese e alterações com o uso agrícola", pelo apoio financeiro; e à Maria Santiso Taboada, técnica do laboratório da USC, pelo auxílio nas análises laboratoriais.

\section{LITERATURA CITADA}

ANDERSON, H.A.; BERROW, M.L.; FARMER, V.C.; HEPBURN, A.; RUSSEL, J.D. \& WALKER, A.D. A reassessment of podzol formation processes. J. Soil Sci., 33:125-136, 1982

BARIL, R. \& BITTON, G. Teneurs élevées de fer libre et l'identification taxonomique de certains sols du Québec contenante de la magnétite. Canadian J. Soil Sci., 59:1-9, 1969 .

BARRETT, L.R. \& SCHAETZL, R.J. An examination of podzolization near Lake Michigan using chronofunctions. Canadian J. Soil Sci., 72:527-541, 1992.

BASCOMB, C.L. Distribution of pyrophosphate-extractable iron and organic carbon in soils of various groups. J. Soil Sci., 19:251-268, 1968.

BLUME, H.P. \& SCHWERTMANN, U. Genetic evaluation of distribution of aluminum, iron, and manganese oxides. Soil Sci. Soc. Am. Proc., 33:438-444, 1969.

BORGGAARD, O.K. Organic matter and silicon in relation to the crystallinity of soil iron oxides. Acta Agric. Scand., 35:398-406, 1985.

BUURMAN, P. Carbon/sesquioxide ratios in organic complexes and the transition albic-spodic horizon. J. Soil Sci., 36:255260, 1985 .

BUURMAN, P.; LAGEN, B. \& VELTHORST, E.J. Manual of soil and water analysis. Leiden, Backhuys Publishers Leiden, 1996. 314p.

CHILDS, C.W.; PARFITT, R.L. \& LEE, R. Movement of aluminum as an inorganic complex in some podzolized soils, New Zealand. Geoderma, 29:139-155, 1983. 
COELHO, M.R. Caracterização e gênese de Espodossolos da planície costeira do Estado de São Paulo. Piracicaba, Escola Superior de Agricultura Luiz de Queiroz, 2008. 270p. (Tese de Doutorado)

COELHO, M.R.; MARTINS, V.M.; VIDAL-TORRADO, P.; SOUZA, C.R.G.; PEREZ, X.L.O. \& VÁSQUEZ, F.M Relação solo-relevo-substrato geológico nas restingas da planície costeira do estado de São Paulo. R. Bras. Ci. Solo, 34:833-846, 2010.

DALHGREN, R.A. \& SAIGUSA, M. Aluminum release rates from allophonic and non allophonic Andosols. Soil Sci. Plant Nutr., 40:125-136, 1994.

DARKE, A.K. \& WALBRIDGE, M.R. Estimating non-crystalline and crystalline aluminum and iron by selective dissolution in a riparian forest soil. Comm. Soil Sci. Plant Anal., 25:2089-2101, 1994.

EMPRESA BRASILEIRA DE PESQUISA AGROPECUÁRIA . EMBRAPA. Centro Nacional de Pesquisa em Solos. Sistema brasileiro de classificação de solos. 2.ed. Rio de Janeiro, 2006. 306p

EMPRESA BRASILEIRA DE PESQUISA AGROCECUÁRIA . EMBRAPA. Centro Nacional de Pesquisa em Solos. Manual de métodos de análise de solo. 2.ed. Rio de Janeiro, 1997. $212 p$.

FARMER, V.C.; FRASER, A.R.; ROBERTSON, L. \& SLEEMAN, J.R. Proto-imogolite allophone in podzol concretions in Australia: Possible relationship to aluminous ferralitic (lateritic) cementation. J. Soil Sci., 35:333-340, 1984.

FARMER, V.C.; RUSSEL, J.D. \& SMITH, B.F.L. Extraction of inorganic forms of translocated $\mathrm{Al}, \mathrm{Fe}$ and $\mathrm{Si}$ from a podzol Bs horizon. J. Soil Sci., 34:571-576, 1983.

FARMER, V.C.; SMITH, B.F.L.; WILSON, M.J.; LOVELAND, P.J. \& PAYTON, R.W. Readily-extractable hydroxyaluminium interlayers in clay- and silt-sized vermiculite. Clay Miner., 23:271-277, 1988.

GARCÍA-RODEJA, E.; NÓVOA, J.C.; PONTEVEDRA, X.; MARTÍNEZ-CORTIZAS, A. \& BUURMAN, P. Aluminium fractionation of European volcanic soils by selective dissolution techniques. Catena, 56:155-183, 2004.

GOMES, F.H.; VIDAL-TORRADO, P.; MACÍAS-VAZQUEZ, F.; GHERARDI, B. \& OTERO, X.L. Solos sob vegetação de restinga na Ilha do Cardoso-SP: I- Caracterização e classificação. R. Bras. Ci. Solo, 31:1563-1580, 2007.

GOMES, J.B.V.; RESENDE, M.; REZENDE, S.B. \& SÁMENDONCCA, E. Solos de três áreas de Restinga. II. Dinâmica de substâncias húmicas, ferro e alumínio. Pesq Agropec. Bras., 33:1921-1932, 1998.

GONZÁLEZ-PÉREZ, M.; VIDAL-TORRADO, P.; COLNAGO, L.A.; MARTIN NETO, L.; OTERO, X.L.; MILORI, D.M.B.P. \& GOMES, F.H. 13C NMR and FTIR spectroscopy characterization of humic acids in Spodosols under tropical rain forest in southeastern Brazil. Geoderma, 146:425433, 2008.

HIGASHI, T.; DE CONINCK, F. \& GELAUDE, F Characterization of some spodic horizons of the Campine (Belgium) with dithionite-citrate, pyrophosphate and sodium hydroxide-tetraborate. Geoderma, 25:131-142, 1981.
HOLMGREN, G.G.S. A rapid citrate-dithionite extractable iron procedure. Soil Sci. Soc. Am. Proc., 31:210-211, 1967.

IYENGAR, S.S.; ZELAZNY, L.W. \& MARTENS, D.C. Effect of photolytic oxalate treatment on soils hydroxyl-interlayered vermiculites. Clays Clay Miner., 29:429-434, 1981.

JANSEN, B.; NIEROP, K.G.J. \& VERSTRATEN, J.M. Mechanisms controlling the mobility of dissolved organic matter, aluminum and iron in podzol B horizons. Europ. J. Soil Sci., 56:537-550, 2005 .

JARVIS, S.C. Forms of aluminum in some acid permanent grassland soils. J. Soil Sci., 37:211-222, 1986.

JEANROY, E. \& GUILLET, B. The occurrence of suspended ferruginous particles in pyrophosphate extracts of some soil horizons. Geoderma, 26:95-106, 1981.

KAISER, K. \& ZECH, W. Defects in estimation of aluminum in humus complexes of podzolic soils by pyrophosphate extraction. Soil Sci., 161:452-458, 1996.

KODAMA, H. \& ROSS, G.J. Tiron dissolution method used to remove and characterize inorganic components in soils. Soil Sci. Soc. Am. J., 55:1180-1186, 1991.

LEE, F.Y.; YUAN, T.L. \& CARLISLE, V.W. Nature of cementing materials in ortstein horizons of selected Florida Spodosols: II. Soil properties and chemical form(s) of aluminum. Soil Sci. Soc. Am. J., 52:1796-1801, 1988.

LUMDSTRÖM, U.S.; van BREEMEN, N. \& BAIN, D. The podzolization process: A review. Geoderma, 94:91-107, 2000 .

McKEAGUE, J.A. An evaluation of 0,1 M pyrophosphate and pyrophosphate-dithionite in comparison with oxalate as extractants of the accumulation products in podzols and some other soils. Canadian J. Soil Sci., 46:12-22, 1967.

McKEAGUE, J.A. \& DAY, J.H. Dithionite and oxalate extractable $\mathrm{Fe}$ and $\mathrm{Al}$ as aids in differentiating various classes of soils. Canadian J. Soil Sci., 46:13-22, 1966.

McKEAGUE, J.A. \& SCHUPPLI, P.A. Changes in concentration of iron and aluminum in pyrophosphate extracts of soil and composition of sediment resulting from ultracentrifugation in relation to spodic horizon criteria. Soil Sci., 134:265-270, 1982.

McKEAGUE, J.A. \& SHELDRICK, B.H. Sodium hydroxidetetraborate in comparison with sodium pyrophosphate as an extractant of "complexes" characteristics of spodic horizons. Geoderma, 19:97-104, 1977.

McKEAGUE, J.A.; BRYDON, J.E. \& MILNES, N.M. Differentiation of forms of extractable iron and aluminum in soils. Soil Sci. Soc. Am. Proc., 35:33-38, 1971.

MEHRA, O.P. \& JACKSON, M.L. Iron oxide removal from soils and clays by dithionite-citrate system buffered with sodium bicarbonate. Clays Clay Miner., 7:317-327, 1960.

MELO, M.R.F. \& MANTOVANI, W. Composição florística e estrutura fitossociológica da mata atlântica de encosta na Ilha do Cardoso (Cananeia, SP, Brasil). B. Inst. Bot.,9:107158,1994

MOKMA, L. \& BUURMAN, P. Podzols and podzolization in temperate regions. Wageningen, International Soil Museum, 1982. 126p. (ISM monograph, 1) 
MOKMA. L. New chemical criteria for defining the spodic horizon. Soil Sci. Soc. Am. J., 47:972-976, 1983.

OLIVEIRA, J.B.; JACOMINE, P.K.T. \& CAMARGO, M.N. Classes gerais de solos do Brasil: Guia auxiliar para seu reconhecimento. 2.ed. Jaboticabal, FUNEP, 1992. 201p.

PARFITT, R.L. \& CHILDS, C.W. Estimation of forms of Fe and $\mathrm{Al}$ : A review, and analysis of contrasting soils by dissolution and Mossbauer methods. Austr. J. Soil Res., 26:121-144, 1988.

PARFITT, R.L. \& HENMI, T. Comparison of an oxalateextraction method and an infrared spectroscopic method for determining allophane in soil clays. Soil Sci. Plant Nutr., 28:183-190, 1982.

PATERSON, E.; CLARK, L. \& BIRNIE, C. Sequential selective dissolution of iron, aluminum, and silicon from soils. Comm. Soil Sci. Plant Anal., 24:2015-1023, 1993.

PETRI, S. \& FÚLFARO, V.J. Nota sobre a geologia e terraços marinhos da Ilha do Cardoso. Notícias Geomorfol., 10:2131, 1970.

SANTOS, R.D.; LEMOS, R.C.; SANTOS, H.G.; KER, J.C. \& ANJOS, L.H.C. Manual de descrição e coleta de solo no campo. 5.ed. Viçosa, MG, Sociedade Brasileira de Ciência do Solo, 2005. 100p.

SAUER, D.; SPONAGEL, H.; SOMMER, M.; GIANI, L.; JAHN, R. \& STAHR, K. Review article - Podzol: Soil of the year 2007 - A review on its genesis, occurrence, and functions. J. Plant Nutr. Soil Sci., 170:581-597, 2007.

SHOJI, S. \& FUJIWARA, Y. Active aluminum and iron in the humus horizons of Andosols from northeastern Japan: Their forms, properties and significance in clay weathering. Soil Sci., 137:216-226, 1984.

SHOJI, S.; FUJIWARA, Y.; YAMADA, I. \& SAIGUSA, M. Chemistry and clay mineralogy of Ando soils, Brown forest soils, and Podzolic soils formed from recent Towada ashes, Northeastern Japan. Soil Sci., 133:69-86, 1982.

SKJEMSTAD, J.O. Genesis of Podzols on Coastal Dunes in Southern Queensland. III. The role of aluminium-organic complexes in profile development. Austr. J. Soil Res., 30:645-665, 1992.

SKJEMSTAD, J.O.; FITZPATRICK, R.W.; ZARCINAS, B.A. \& THOMPSON, C.H. Genesis of Podzols on Coastal Dunes in Southern Queensland. II. Geochemistry and forms of elements as deduced from various soil extraction procedures. Austr. J. Soil Res., 30:615-644, 1992a.
SKJEMSTAD, J.O.; WATERS, A.G.; HANNA, J.V. \& OADES, J.M. Genesis of Podzols on Coastal Dunes in Southern Queensland. II. Nature of the organic fraction as seen by ${ }^{13} \mathrm{C}$ nuclear magnetic resonance spectroscopy. Austr. J. Soil Res., 30:615-644, 1992b.

SOON, Y.K. Fractionation of extractable aluminum in acid soils: A review and a proponed procedure. Comm. Soil Sci. Plant Anal., 24:1683-1708, 1993.

STEVENSON, F.J. Humus chemistry: Genesis, composition and reactions. New York, Wiley, 1982. 443p.

TAKAHASHI, T.; FUKUOKA, T. \& DAHLGREN, R.A. Aluminum solubility and release rates from soil horizons dominated by aluminum-humus complexes. Soil Sci. Plant Nutr., 41:119-131, 1995.

SUGUIO, K. \& MARTIN, L. Mapa geológico do litoral de São Paulo, Escala 1:100.000. Folha de Bertioga. São Paulo, Secretaria de Obras e Meio Ambiente / Departamento de Águas e Energia Elétrica, 1978.

SUGUIO, K. \& TESSLER, M.G. Planícies de cordões litorâneos quaternários do Brasil: Origem e nomenclatura. In: LACERDA, L.D.; ARAÚJO, D.S.D. \& CERQUEIRA, R.; TURQ, B. Restingas: Origem, estrutura e processos. Niteroi, CEUFF, 1984. p.15-26.

URRUTIA, M.; MACÍAS, F. \& GARCÍA-RODEJA, E. Evaluación del $\mathrm{CuCl}_{2}$ y del $\mathrm{LaCl}_{3}$ como extractantes de aluminio en suelos ácidos de Galicia. Nova Acta Ci.; Biología, 5:173-182, 1995.

van BREEMEN, N. \& BUURMAN, P. Soil formation. 2.ed. Dordrecht, Kluwer Academic Publishers, 2002. 404p.

van RANST, E. STOOPS, G.; GALLEZ, A. \& VANDENBERGHE, R.E. Properties, some criteria of classification and genesis of upland forest Podzols in Rwanda. Geoderma, 76:263-283, 1997.

WADA, K. Mineralogical characteristics of Andisols. In: THENG, B.K., ed. Soil with variable charge. Palmerston North, New Zealand Society of Soil Science, 1980. p.87107.

WADA, K. Allophane and imogolite. In: DIXON, J.B. \& WEED, S.B., eds. Minerals in soil environments. Madison, Soil Science Society of America, 1977. p.603-638.

WADA, K. \& HIGASHI, T. The categories of aluminum- and iron-humus complexes in Ando soils determined by selective dissolution. J. Soil Sci., 27:357-368, 1976. 